\title{
Cultural Adaptation and Psychometric Properties of the Diabetes Quality of Life Scale in Afaan Oromoo Among People Living With Type 2 Diabetes in Ethiopia
}

\section{Dereje Chala Diriba}

The Hong Kong Polytechnic University School of Nursing https://orcid.org/0000-0003-2432-7326

\section{Doris Y.P. Leung}

The Hong Kong Polytechnic University School of Nursing

Lorna K.P. Suen ( $\square$ lornasuen@twc.edu.hk)

Tung Wah College, Kowloon https://orcid.org/0000-0002-0126-6674

\section{Research}

Keywords: Diabetes quality of life, DQOL, Afaan Oromoo, psychometric properties

Posted Date: May 25th, 2021

DOI: https://doi.org/10.21203/rs.3.rs-535822/v1

License: (c) (1) This work is licensed under a Creative Commons Attribution 4.0 International License.

Read Full License 


\section{Abstract}

Background: The original 46-item Diabetes Quality of Life (DQOL) scale has been translated into different languages, and the translated DQOL has shown good reliability and validity after deleting some items. However, the DQOL is not available in the Afaan Oromoo language for people living with type 2 diabetes (T2D) in Ethiopia. The objective of the study was to translate the DQOL scale into Afaan Oromoo, and to culturally adapt and evaluate the psychometric properties of the DQOL-Afaan Oromoo (DQOL-AO) among people living with T2D in Ethiopia.

Methods: A cross-sectional study with a convenience sampling technique was conducted in 2020 . The DQOL was translated and adapted to Afaan Oromoo. Item-total correlations and exploratory factor analysis (EFA) assessed factor structure; the Cronbach's alpha assessed internal consistency and relationships with gender, educational status, marital status, age, employment status; and status of diabetes-related disease assessed the construct validity of the DQOL-AO.

Results: A 417 participants responded to all items of the DQOL. Item-total correlation analysis and EFA produced a 34-item DQOL-AO with four subscales, which demonstrated that the internal consistency of the overall DQOL-AO was 0.867 , and scores were $0.827,0.846,0.654,0.727$ for the impact, satisfaction, social/vocational worry, and diabetes-related worry subscales, respectively. Statistically significant differences in QOL were obtained in educational status $(F=7.164, p<0.001)$ and employment status $(F=4.21, P=0.002)$. Individuals who attended college and above and government employees had better QOL.

Conclusion: The 34-item DQOL-AO provided preliminary evidence as a reliable and valid tool to measure diabetic-related QOL among adults living with T2D who speak Afaan Oromoo.

\section{Introduction}

Diabetes is one of the most prevalent non-communicable diseases and the cause of a major global public health problem [1]. The International Diabetes Federation (IDF) estimates that 463 million adults worldwide have diabetes; four million of them die every year [2]. Diabetes is running rampant globally, with the IDF projecting that there will be 700 million adults living with diabetes in 2045 . The burden of the disease is devastating in middle-and low-income countries (13.5\%). An alarming increment of $143 \%$ is expected in Africa, which will have 47 million cases-the highest predicted increase of all the IDF regionsif crucial action is not taken immediately. Over 19 million adults were living with diabetes in Africa in 2019, with Ethiopia accounting for 1.7 million (3.2\%) [2].

Quality of life (QOL) in people living with diabetes becomes a daily goal and is considered an important treatment outcome. It has been argued that QOL measures not only what is important to them but also how good their life is [3]. QOL assesses the physiological well-being, physical, and psychosocial aspects, and lived experience of patients. Several studies have reported that diabetes negatively affects a person's QOL [4-6]. Diabetes poses social, physical, sexual and physiological impacts, and these impacts are 
worse if complications develop [5-7]. Although QOL is recognized as an important patient-reported outcome, it is rarely assessed in diabetes research [8]. A recent study of 25 years' experience of the impact of diabetes assessment study pointed out that the QOL needs to be addressed by researchers as a priority [9].

Measuring QOL in people living with diabetes is imperative in order to understand their QOL [4]. Compared to generic tools, diabetes-related QOL is better measured by diabetes-specific tools [10]. Diabetes-specific tools are designed to measure the specific content, disease condition, and target population [11-13]. Even though various forms of diabetes-specific QOL measures are available, the diabetes quality of life (DQOL) scale provides a comprehensive assessment of the components of QOL among people living with diabetes in general; it has been widely used in different studies to measure QOL among people living with diabetes [14-17] and is sensitive to disease severity and lifestyle changes [18].

The DQOL scale was originally developed in 1988 by the diabetes control and complications trial research group in English, in a study aimed to evaluate the effects of two different diabetes treatment regimens on QOL. The DQOL has 46 items measuring four domains: satisfaction, impact, social/vocational worry and diabetes-related worry [19]. Subsequently, numerous shortened versions of the DQOL were produced in different languages [14, 17, 20-22]. A 24-item Chinese version [17], a 44-item Brazilian DQOL version [21], an 8-item Brazilian brief version [20], a 45-item Turkish version [22], a 46-item Iranian version [23] and a 13-item Malay revised version were developed [14]; all showed acceptable validity and reliability. Consistent with the original version of the DQOL, all the shortened versions of the DQOL have four domains, with one exception: the 13-item Malay revised version [14] measures three domains, namely satisfaction, impact, and worry. Some studies have also reported that some items of the DQOL had a low correlation with items in the same domain $[15,17]$, thus it is deemed necessary to establish the correlation matrix among items in the domain. The DQOL scale Cronbach's alpha ranged from 0.702 to $0.92[19,20,22,23]$.

Regarding the construct validity of the DQOL, studies have demonstrated that educational status, employment status, age and comorbidity status were significantly related to QOL among adults living with diabetes. Specifically, people living with diabetes who were female and married scored significantly higher than their male counterparts, while people living with diabetes who had not attended formal education, were older, were separated/widowed, were unemployed, and people living with diabetes complications scored significantly lower in QOL [18, 24-26].

Though the DQOL scale is available in different language versions, there is no translated, culturally adapted, and psychometrically validated version in Afaan Oromoo, which is the most widely spoken language in Ethiopia (33.8\%) and is the fourth most widely spoken language in Africa [27]. Hence, this study aimed to translate the original English version of the DQOL into Afaan Oromoo and culturally adapt and evaluate its factor structure, reliability, and construct validity among adults living with Type 2 diabetes (T2D) in Ethiopia. 


\section{Methods}

\section{Study design}

A cross-sectional study design was employed to examine the psychometric properties of the Afaan Oromoo version of the DQOL measure.

\section{Participants}

A convenience sampling technique was used to recruit people living with T2D attending the diabetes center of Nekemte Specialized Hospital in Western Ethiopia for their monthly medical check-up between June and August 2020. Included among the people living with T2D were those who 1) had been treated at the diabetes center in the hospital for six months or more; 2 ) were in a stable medical condition; 3 ) were aged 18 or over; 4) were cognitively intact, and 5) were able to speak and understand Afaan Oromoo. People living with Type 2 diabetes were excluded if they had a hearing problem.

Ethical approval for the study was obtained from The Hong Kong Polytechnic University. Permission to collect data was obtained from the hospital administrator before the start of the study and informed written consent was obtained from the participants. The confidentiality of the data was ensured through coding.

\section{Translation of the DQOL}

Permission to translate and adapt the 46-item DQOL scale was obtained from the scale developers. The DQOL was translated and culturally adapted into Afaan Oromoo according to the six-stage recommendation of cross-cultural adaptation developed by the Institute for Work and Health in 2007 [28]. In stage 1, two versions of the forward translation of the original version of the DQOL were prepared by two translators (a health professional and a naïve translator who is a Ph.D. holder in Afaan Oromoo). In stage 2, a synthesis of the translations obtained in stage 1 was made by the principal researcher, and a reconciled translation of the scale was developed after agreement on any discrepancies was reached. In stage 3, two separate versions of the back-translation of the scale were prepared by another two excellent translators, who were Ph.D. holders in English and native speakers of Afaan Oromoo. In stage 4, an expert panel consisting of seven professionals (one public health expert, one nurse, one Afaan Oromoo language expert, two forward and two backward translators) was formed and they evaluated conceptual, semantic, and idiomatic equivalences of the translated versions of the scale using five-point Likert scale items to calculate the content validity index $(\mathrm{CVI})$. Discrepancies were resolved through discussion until consensus was reached. The CVI of the Afaan Oromoo version of the DQOL tool was $\geq 0.95$. In stage 5 , 30 people living with T2D were asked to assess the applicability, readability, and clarity of the item content of the expert-evaluated version of the scale [29]. The cultural adaptation was made using locally spoken and acceptable words. The people living with diabetes were requested to suggest the appropriate terms, and amendments were done to the local culture. In stage 6 , an amendment was made based on feedback from the participants, using appropriate words and restructuring some sentences in a culturally 
appropriate way, and the final version of the scale in Afaan Oromoo, the Diabetes Quality of Life-Afaan Oromoo (DQOL-AO), was developed and subjected to psychometric testing.

\section{Sample size calculation}

For psychometric testing, the required sample size was determined based on exploratory factor analysis (EFA) using the case-to-variable (rule of thumb) of 10:1 ratio. A minimum sample size of 460 was included.

\section{Instrument}

The 46-item DQOL has four major domains: satisfaction (15 items), impact (20 items), social/vocational worry ( 7 items), and diabetes-related worry (4 items). Items in the satisfaction domain are scored on a five-point scale ranging from 1 (very satisfied) to 5 (very dissatisfied), and items in the impact and the two worry domains are scored on a five-point scale, ranging from 1 (no impact and never worried) to 5 (always impacted and always worried). If an item is not relevant to the respondent, the 'Does not apply' option is provided for the social/vocational worry and diabetes-related worry subscales and will not be scored. A lower score in DQOL indicates a better QOL [18].

Sociodemographic variables, namely gender, marital status, ethnicity, religion, educational level, family member usually providing support, and employment status, and patient-related factors such as the diabetes-specific complication (s) and year of first disease diagnosis were collected.

\section{Data collection procedure}

Eight data collectors who have experience in data collection were trained in a one-day workshop to ensure they were familiar with and understood the items in the scale and the techniques of conducting interviews for the study. People living with diabetes were approached when they were waiting to see the doctor in the diabetes center of the hospital. After explaining the purpose and study procedure, the data collectors screened the people living with diabetes for their eligibility. Having obtained their informed written consent, the data collectors then administered the questionnaire via face-to-face interviews.

\section{Statistical analysis}

All data analyses were conducted using SPSS statistics version 25. The factor structure of the DQOL-AO was examined in two steps. In step 1, item reduction based on the item-total correlation was performed. Any item with an item-total correlation coefficient below 0.3 was removed [30, 31]. In step 2, EFAs were conducted on the items remaining after step 1. The Kaiser-Meyer-Olkin (KMO) and Barlett's tests checked for the appropriateness of conducting EFA. The factor retention was based on four criteria: (i) eigenvalues $>1$; (ii) scree plot; (iii) interpretability of the retained factors; and (iv) factor loadings $>0.4$. For items cross-loaded on factors, the retention of the item to the factor was determined by two criteria: 1) a higher loading effect of the item onto the factor and 2 ) the interpretability of the item. The Cronbach's alpha value was then calculated to assess the reliability of the subscales and the overall scale of the DQOL-AO. 
Ceiling and floor effect analysis for subscales and the overall scale were performed to distinguish the proportion of respondents with the highest and lowest QOL scores, respectively [32]. Ceiling or floor effects were judged if more than $15 \%$ of subjects reached the highest or lowest score, respectively [33].

The construct validity of the DQOL-AO was assessed by the known group and correlation analysis Pearson's correlation was used for continuous demographic variables and an independent t-test or ANOVA was used for categorical variables. In all the analyses, a $P$-value $<0.05$ was considered statistically significant.

\section{Results}

A total of 460 adults living with T2D attending hospital were recruited between June and August 2020. The rate of missing data in at least one of the 46 items was low (9.4\%), and data analyses were done on the completed cases, which represented $90.6 \%$ of total cases $(417 / 460)$. The mean age of the participants was 50.2 years ( $S D \pm 11.7$ ); $51.3 \%$ were female, $77.5 \%$ were married and $88.2 \%$ were Oromoo. More than half, $56.8 \%$ of the respondents, were Protestant Christian, and the majority $(61.6 \%)$ received support from their spouse, followed by their children. One-third (33.1\%) of the participants had attended $\leq$ grade 8 , with the next-largest group having attended college or above $(24.5 \%) ; 27.2 \%$ of the respondents were employees of a private organization, while $20.6 \%$ were retired or disabled. More than half $(55.4 \%)$ of the people living with diabetes had comorbid diseases, and nearly half (45.6\%) had hypertension. More than three-quarters $(82.7 \%)$ had $\leq 10$ years of history of diabetes (Table 1$)$. 
Table 1

Sociodemographic characteristics of people living with type 2 diabetes attending Nekemte Specialized Hospital, 2020 ( $n=417)$

\begin{tabular}{|c|c|}
\hline Variables with categories & Frequency (\%) \\
\hline Age in years & Mean $50.2(S D \pm 11.7)$ \\
\hline \multicolumn{2}{|l|}{ Gender } \\
\hline Female & $214(51.3 \%)$ \\
\hline Male & $203(48.7 \%)$ \\
\hline \multicolumn{2}{|l|}{ Marital status } \\
\hline Married & $323(77.5 \%)$ \\
\hline Never married & $30(7.2 \%)$ \\
\hline Separated/widowed & $64(15.3 \%)$ \\
\hline \multicolumn{2}{|l|}{ Ethnicity } \\
\hline Oromoo & $368(88.2 \%)$ \\
\hline Amhara & $43(10.3 \%)$ \\
\hline Other & $6(1.4 \%)$ \\
\hline \multicolumn{2}{|l|}{ Religion } \\
\hline Protestant Christian & $237(56.8 \%)$ \\
\hline Orthodox Christian & $138(33.1 \%)$ \\
\hline Muslim & $34(8.2 \%)$ \\
\hline Other & $8(1.9 \%)$ \\
\hline \multicolumn{2}{|l|}{$\begin{array}{l}\text { Primary caregiver (support } \\
\text { provider) }\end{array}$} \\
\hline Spouse & $123(29.5 \%)$ \\
\hline $\begin{array}{l}\text { Children } \\
\text { Mother or father }\end{array}$ & $37(8.9 \%)$ \\
\hline \multicolumn{2}{|l|}{ Educational status } \\
\hline No formal education & $76(18.2 \%)$ \\
\hline Elementary school ( $\leq$ grade 8 ) & $138(33.1 \%)$ \\
\hline Secondary school (grade 9-12) & $101(24.2 \%)$ \\
\hline College and above & $102(24.5 \%)$ \\
\hline
\end{tabular}




\begin{tabular}{|ll|}
\hline Variables with categories & Frequency (\%) \\
\hline Employment status & \\
Government employees & $76(18.2 \%)$ \\
Private organization employee & $113(27.2 \%)$ \\
Unemployed & $73(17.5 \%)$ \\
Retired/disabled & $86(20.6 \%)$ \\
Farmer & $69(16.5 \%)$ \\
\hline $\begin{array}{l}\text { Presence of disease-related } \\
\text { disease }\end{array}$ & $231(55.4 \%)$ \\
Yes & $186(44.6 \%)$ \\
No & \\
\hline Type of disease-related disease & $190(82.3 \%)$ \\
Hypertension & $41(17.7 \%)$ \\
Other diseases & \\
\hline Years since diagnosis of diabetes & \\
$\leq 10$ & $72(17.3 \%)$ \\
$>10$ & \\
\hline
\end{tabular}

\section{Factor structure}

\section{Item-total correlation}

Based on the item-total correlation statistics, a total of 12 items had item-total correlation $<0.3$ (Table 2). These included two items (items 7 and 15) from the satisfaction subscale; seven items (items 3, 8, 16, 17, 18, 19 and 20) from the impact subscale; two items (items 4 and 5) from the social/vocational worry subscale and one item (item 4) from the diabetes-related worry subscale. The items were removed from the $A O$ version of the DQOL. A total of 34 items were retained in the scale: satisfaction (13 items), impact (13 items), social/vocational worry (6 items), and diabetes-related worry (3 items). These items were subjected to EFA. 
Table 2

Item-total statistics of the DQOL-AO version among adults living with type 2 diabetes attending Nekemte Specialized Hospital, $2020(\mathrm{n}=417)$.

\section{Item Domain and items number}

Item-total correlation

\section{Satisfaction}

1. How satisfied are you with the amount of time it takes to manage your diabetes?

2. How satisfied are you with the amount of time you spend getting checkups?

3. How satisfied are you with the time it takes to determine your sugar level?

4. How satisfied are you with your current treatment?

5. How satisfied are you with the flexibility you have in your diet?

6. How satisfied are you with the burden your diabetes is placing on your family?

7. How satisfied are you with your knowledge about your diabetes?

8. How satisfied are you with your sleep?

9. How satisfied are you with your social relationships and friendships?

10. How satisfied are you with your sex life?

11. How satisfied are you with your work, school, and household activities?

12. How satisfied are you with the appearance of your body?

13. How satisfied are you with the time you spend exercising?

14. How satisfied are you with your leisure time?

15. How satisfied are you with life in general?

Impact

1. How often do you feel the pain associated with the treatment of your .363 diabetes?

2. How often are you embarrassed by having to deal with your diabetes in .303 public?

3. How often do you have low blood sugar?

4. How often do you feel physically ill?

5. How often does your diabetes interfere with your family life?

6.

How often do you have a bad night's sleep? 


\section{Item Domain and items

7. How often do you find your diabetes limiting your social relationships and

.486 friendships?

8. How often do you feel good about yourself?

9. How often do you feel restricted by your diet?

10. How often does your diabetes interfere with your sex life?

11. How often does your diabetes keep you from driving a car or using a .522 machine (e.g., a typewriter)?

12. How often does your diabetes interfere with your exercising?

13. How often do you miss work, school, or household duties because of your diabetes?

14. How often do you find yourself explaining what it means to have diabetes?

15. How often do you find that your diabetes interrupts your leisure-time activities?

16. How often do you tell others about your diabetes?

17. How often are you teased because you have diabetes?

18. How often do you feel that because of your diabetes you go to the bathroom more than others?

19. How often do you find that you eat something you shouldn't rather than tell someone that you have diabetes?

20. How often do you hide from others the fact that you are having an insulin reaction?

\section{Social/Vocational Worry}

1. How often do you worry about whether you will get married?

2. How often do you worry about whether you will have children?

3. How often do you worry about whether you will not get a job you want?

4.

How often do you worry about whether you will be denied insurance?

5. How often do you worry about whether you will be able to complete your education?

6. How often do you worry about whether you will miss work?

7. How often do you worry about whether you will be able to take a vacation .358 or a trip?

Diabetes-Related Worry 


\begin{tabular}{|llc|}
\hline $\begin{array}{l}\text { Item } \\
\text { number }\end{array}$ & Domain and items & $\begin{array}{c}\text { Item-total } \\
\text { correlation }\end{array}$ \\
\hline 1. & How often do you worry about whether you will pass out? & .496 \\
\hline 2. & $\begin{array}{l}\text { How often do you worry that your body looks different because you have } \\
\text { diabetes? }\end{array}$ & .574 \\
\hline 3. & $\begin{array}{l}\text { How often do you worry that you will get complications from your } \\
\text { diabetes? }\end{array}$ & .407 \\
\hline 4. & $\begin{array}{l}\text { How often do you worry about whether someone will not go out with you } \\
\text { because you have diabetes? }\end{array}$ & .116 \\
\hline
\end{tabular}

\section{Exploratory factor analysis}

An EFA was conducted to examine the factor structure of the remaining 34 items of the DQOL-AO. The KMO statistic was 0.865 and Bartlett's test statistic was $5739.562(p<0.001)$, implying sampling adequacy and appropriateness for factor analysis. The scree plot and eigenvalues suggested four possible factor solutions, namely, 4-, 5-, 6-, and 7-solution. Based on the interpretability of the factors, the 4-factor solution was selected because it produced four explicit factors that resembled the original DQOL. The findings of EFA showed a 4 -factor solution comprising $45.12 \%$ of the total variance retained. All the factor loadings of the 4 -factor solution were greater than 0.4 , hence all 34 items in the DQOL-AO were retained.

The items were examined with their loadings on factors following the original version. Any item that loaded on (an) other subscale(s) in addition to its original subscale was retained in its original subscale only to enhance the interpretability. Finally, 13 items were retained under the impact subscale, 13 in the satisfaction subscale, five in the social/vocational worry subscale, and three in the diabetes-related worry subscale. All 34 items were retained as the DQOL-AO version by EFA (Table 3). 
Table 3

Initial EFA results of the DQOL-AO version among adults living with type 2 diabetes attending Nekemte Specialized Hospital, $2020(\mathrm{n}=417)$.

\begin{tabular}{|c|c|c|c|c|}
\hline \multirow{2}{*}{$\begin{array}{l}\text { Item } \\
\text { number }\end{array}$} & \multicolumn{4}{|c|}{ Factor loading } \\
\hline & $\begin{array}{l}\text { Factor } \\
1\end{array}$ & $\begin{array}{l}\text { Factor } \\
2\end{array}$ & $\begin{array}{l}\text { Factor } \\
3\end{array}$ & $\begin{array}{l}\text { Factor } \\
4\end{array}$ \\
\hline
\end{tabular}

Satisfaction

1. How satisfied are you with the amount of time it

$-.742 \quad .503$ takes to manage your diabetes?

2. How satisfied are you with the amount of time you

$-.705 \quad .569$ spend getting check-ups?

3. How satisfied are you with the time it takes to determine your sugar level?

$-.342 \quad .510$

4. How satisfied are you with your current treatment?

$-.536$

5. How satisfied are you with the flexibility you have

$-.352$

.321 in your diet?

6. How satisfied are you with the burden your diabetes is placing on your family?

.374

7. How satisfied are you with your sleep?

$-.546$

8. How satisfied are you with your social relationships $\quad .423 \quad-.448$ and friendships?

9. How satisfied are you with your sex life?

10. How satisfied are you with your work, school, and $\quad .726$ household activities?

11. How satisfied are you with the appearance of your body?

12. How satisfied are you with the time you spend exercising?

13. How satisfied are you with your leisure time? .500 Impact

1. How often do you feel the pain associated with the .453 treatment of your diabetes?

.567 


\begin{tabular}{|c|c|c|c|c|c|}
\hline \multirow{2}{*}{$\begin{array}{l}\text { Item } \\
\text { number }\end{array}$} & \multirow[t]{2}{*}{ Item } & \multicolumn{4}{|c|}{ Factor loading } \\
\hline & & $\begin{array}{l}\text { Factor } \\
1\end{array}$ & $\begin{array}{l}\text { Factor } \\
2\end{array}$ & $\begin{array}{l}\text { Factor } \\
3\end{array}$ & $\begin{array}{l}\text { Factor } \\
4\end{array}$ \\
\hline 5. & How often do you have a bad night's sleep? & & -.560 & & \\
\hline 6. & $\begin{array}{l}\text { How often do you find your diabetes limiting your } \\
\text { social relationships and friendships? }\end{array}$ & .431 & & & \\
\hline 7. & How often do you feel restricted by your diet? & .401 & & & \\
\hline 8. & $\begin{array}{l}\text { How often does your diabetes interfere with your } \\
\text { sex life? }\end{array}$ & .502 & -.308 & & \\
\hline 9. & $\begin{array}{l}\text { How often does your diabetes keep you from } \\
\text { driving a car or using a machine (e.g., a } \\
\text { typewriter)? }\end{array}$ & .775 & & & \\
\hline 10. & $\begin{array}{l}\text { How often does your diabetes interfere with your } \\
\text { exercising? }\end{array}$ & .709 & & & \\
\hline 11. & $\begin{array}{l}\text { How often do you miss work, school, or household } \\
\text { duties because of your diabetes? }\end{array}$ & .614 & & & \\
\hline 12. & $\begin{array}{l}\text { How often do you find yourself explaining what it } \\
\text { means to have diabetes? }\end{array}$ & .478 & & & \\
\hline 13. & $\begin{array}{l}\text { How often do you find that your diabetes interrupts } \\
\text { your leisure-time activities? }\end{array}$ & .555 & & .359 & \\
\hline \multicolumn{6}{|c|}{ Social/Vocational Worry } \\
\hline 1. & $\begin{array}{l}\text { How often do you worry about whether you will get } \\
\text { married? }\end{array}$ & & .587 & .306 & \\
\hline 2. & $\begin{array}{l}\text { How often do you worry about whether you will } \\
\text { have children? }\end{array}$ & & .475 & .500 & \\
\hline 3. & $\begin{array}{l}\text { How often do you worry about whether you will not } \\
\text { get a job you want? }\end{array}$ & & & .760 & \\
\hline 4. & $\begin{array}{l}\text { How often do you worry about whether you will } \\
\text { miss work? }\end{array}$ & & & .673 & \\
\hline 5. & $\begin{array}{l}\text { How often do you worry about whether you will be } \\
\text { able to take a vacation or a trip? }\end{array}$ & & & .389 & \\
\hline \multicolumn{6}{|c|}{ Diabetes-Related Worry } \\
\hline 1. & $\begin{array}{l}\text { How often do you worry about whether you will } \\
\text { pass out? }\end{array}$ & & & & .765 \\
\hline 2. & $\begin{array}{l}\text { How often do you worry that your body looks } \\
\text { different because you have diabetes? }\end{array}$ & & & & .745 \\
\hline 3. & $\begin{array}{l}\text { How often do you worry that you will get } \\
\text { complications from your diabetes? }\end{array}$ & & & & .725 \\
\hline
\end{tabular}




\section{Reliability estimate}

The finding of the DQOL-AO shown good internal consistency $(>0.7)$ in three subscales (impact, satisfaction, and diabetes-related worry), but the social/vocation worry subscale has questionable internal consistency $(a=0.654)$ (Table 4$)$.

Table 4

The internal consistency, ceiling, and floor effects of the DQOL-AO version among people living with type 2 diabetes attending Nekemte Specialized Hospital, $2020(n=417)$.

\begin{tabular}{|llllll|}
\hline Scale/subscale & $\begin{array}{l}\text { Number of } \\
\text { items }\end{array}$ & $\begin{array}{l}\text { Cronbach's } \\
\text { alpha }\end{array}$ & $\begin{array}{l}\text { Mean score }( \pm \\
\text { SD) }\end{array}$ & $\begin{array}{l}\text { Ceiling } \\
\text { effect } \\
\mathbf{n}(\%)\end{array}$ & $\begin{array}{l}\text { Floor } \\
\text { effect } \\
\mathbf{n}(\%)\end{array}$ \\
\hline Impact & 13 & 0.827 & $2.43(0.49)$ & $2(0.5)$ & $1(0.2)$ \\
\hline Satisfaction & 13 & 0.846 & $2.46(0.56)$ & $1(0.2)$ & $1(0.2)$ \\
$\begin{array}{l}\text { Social/vocational } \\
\text { worry }\end{array}$ & 5 & 0.654 & $1.53(0.93)$ & $26(6.2)$ & $2(0.5)$ \\
\hline $\begin{array}{l}\text { Diabetes-related } \\
\text { worry }\end{array}$ & 3 & 0.727 & $3.20(0.65)$ & $2(0.5)$ & $4(1.0)$ \\
\hline Total DQOL & 34 & 0.867 & $2.38(0.43)$ & $1(0.2)$ & $1(0.2)$ \\
\hline
\end{tabular}

The ceiling and floor effects of the items were calculated for the scale and subscales of the DQOL-AO version. A very small proportion of the people living with diabetes $(\leq 1.0 \%)$ attained the highest QOL score, and $\leq 6.2 \%$ of the study participants achieved the lowest QOL score in all four subscales. For the overall DQOL-AO scale, there was also no evidence of any ceiling or floor effect (0.2\%) (Table 4).

\section{Construct validity}

The results of ANOVA showed that education status $(F=7.164, P<0.001)$ and employment status $(F=$ 4.211, $P=0.02$ ) demonstrated a significant difference in the DQOL-AO scores of the participants. There was a significant difference between participants who attended college and above $(2.23 \pm 0.40)$ and those who had not attended formal education $(2.43 \pm 0.43, P=0.008)$ or attended only elementary school $(2.47 \pm 0.42, P<0.001)$. However, those who attended college and above had better QOL (Table 5). There was also a significant difference between government employees $(2.23 \pm 0.39)$ and those who were retired/disabled $(2.44 \pm 0.39, P=0.014)$ or farmers $(2.39 \pm 0.44, P=0.002)$ : better QOL was revealed among government employees (Table 5). There was no statistically significant difference in QoL with other variables. 
Table 5

Relationships between DQOL-AO scores and demographic variables and pairwise comparison among people living with type 2 diabetes attending Nekemte Specialized Hospital, 2020 ( $n=417)$.

\begin{tabular}{|c|c|c|c|c|c|}
\hline Variables with categories & $\begin{array}{l}\text { Frequency } \\
\text { (n) }\end{array}$ & $\begin{array}{l}\text { Mean } \\
\text { score }\end{array}$ & SD & $\begin{array}{l}\text { Between- } \\
\text { group } P \\
\text { value }\end{array}$ & Pairwise comparison \\
\hline \multicolumn{6}{|l|}{ Gender } \\
\hline Female & 214 & 2.40 & 0.42 & 0.288 & \\
\hline Male & 203 & 2.36 & 0.42 & & \\
\hline Age & 217 & $\begin{array}{l}r= \\
0.057\end{array}$ & & 0.247 & \\
\hline \multicolumn{6}{|l|}{$\begin{array}{l}\text { Diabetes-specific } \\
\text { complication (s) status }\end{array}$} \\
\hline No & 186 & 2.35 & 0.43 & 0.163 & \\
\hline & 231 & 2.41 & 0.42 & & \\
\hline \multicolumn{6}{|l|}{ Marital status } \\
\hline Married & 323 & 2.36 & 0.42 & 0.352 & \\
\hline Never married & 30 & 2.43 & 0.47 & & \\
\hline Separated/widowed & 64 & 2.44 & 0.43 & & \\
\hline Educational status & & & & & $\begin{array}{l}\text { College and above < } \\
\text { elementary school, no }\end{array}$ \\
\hline No formal education & 76 & 2.43 & 0.43 & $<0.001$ & formal education \\
\hline Elementary school ( $\leq$ & 138 & 2.47 & 0.42 & & \\
\hline $\begin{array}{l}\text { Secondary school (grade } \\
9-12 \text { ) }\end{array}$ & $\begin{array}{l}101 \\
102\end{array}$ & $\begin{array}{l}2.37 \\
2.23\end{array}$ & $\begin{array}{l}0.42 \\
0.40\end{array}$ & & \\
\hline \multicolumn{6}{|l|}{ College and above } \\
\hline Employment status & & & & & $\begin{array}{l}\text { Government } \\
\text { employees }<\end{array}$ \\
\hline Government employees & 76 & 2.23 & 0.39 & 0.02 & retired/disabled, farmer \\
\hline $\begin{array}{l}\text { Private organization } \\
\text { emplovees }\end{array}$ & 113 & 2.35 & 0.45 & & \\
\hline Unemploved & 73 & 2.39 & 0.41 & & \\
\hline Retired/disabled & 86 & 2.44 & 0.39 & & \\
\hline Farmer & 69 & 2.39 & 0.44 & & \\
\hline
\end{tabular}


By contrast, diabetes-related complication(s) ( $\mathrm{t}=-1.397, P=0.163)$, marital status $(\mathrm{F}=1.047, P=0.352)$, and gender ( $\mathrm{t}=-1.064, P=0.288$ ) showed non-significant results. In addition, a non-significant but positive correlation between age and DQOL-AO ( $r=0.057, P=0.242)$ was obtained (Table 5).

\section{Discussion}

The original version of the DQOL scale was translated to Afaan Oromoo according to cross-cultural adaptation guidelines. The content validity of the translated version was evaluated by experts and demonstrated acceptable CVI [34]. The DQOL-AO version was found to be reliable and valid to measure QOL among adults living with T2D who speak Afaan Oromoo. The DQOL-AO consists of 34 items, and a four-factor solution was retained in the EFA. The four factors found were consistent with the original, Brazilian, Brazilian brief, Chinese, and Turkish versions of the scale [17, 19-22], but inconsistent with the Malay version $[14,15]$.

The seven dropped items (impact items 3,16, 19 and 20; social/vocational worry items 4 and 5; and diabetes-related worry item 4) in this DQOL-AO version were consistent with the deleted items in the revised Malay version [14]. On the other hand, the removed satisfaction item 7; impact items 8, 16, 17, 19 and 20; and social/vocational worry item 5 accord with the items removed in the Chinese version [17]. Four items: satisfaction item 7, and impact items 3, 8, and 17, were removed in this version, also consistent with items removed in the Chinese and brief DQOL-Brazil-8 versions [17, 20]. That these items were removed in different versions may indicate that they are less important for assessing the QOL of adults living with diabetes. On the other hand, satisfaction items 7 and 15 are redundant in terms of expressing QOL among adults living with diabetes. Similarly, impact items 4 and 16 are comparable, thus impact item 16 was removed due to redundancy [14]. Impact item 20 was removed, possibly since the vast majority of people living with T2D do not receive insulin, hence an insulin reaction is not expected and is not a relevant item [35]. The social/vocational worry items 4 and 5 were removed from the subscale. This might be because most respondents were employed or retired and might not worry about employment.

The DQOL-AO also had good internal consistency. This was similar to the Turkish and Chinese versions $[17,22]$. The impact subscale showed better internal consistency when compared with the original [19] and a revised Malay version [14], and was consistent with the Chinese [17] and Turkish versions [22]. The satisfaction subscale's internal consistency revealed good reliability that was in line with the original version [19] and inconsistent with the revised 13-item Malay, Malay, Chinese, and Turkish versions [14, 15, $17,22]$. While diabetes-related worry demonstrated good internal consistency, that of social/vocational worry was questionable. These findings were inconsistent with the original, Chinese, Turkish, Malay, and revised Malay versions $[14,15,17,22]$, but the low level of internal consistency resembled the original version [19]. The possible variation in internal consistency in worry maybe because most people living 
with diabetes were married and employed. Another explanation for the low level of internal consistency among worry items might be that there were fewer items in the domain [36].

The known-group analyses showed that educational and employment status were significant predictors of QOL among people living with T2D. Attending college and above education and working in government institutions were related to better QOL. These findings were consistent with the study conducted in Botswana and Gondar, Ethiopia among people living with diabetes, which revealed that those who were educated and employed had better QOL $[26,37]$. No significant correlation was established between the age of the patient and overall QOL, inconsistent with the study report by Jacobson and de Groot [18]. Females tended to show a lower QOL, which was like the finding in the Chinese population [38]. However, the presence of diabetes-related disease(s), marital status, and the gender of people living with diabetes revealed non-significant findings that were inconsistent with those from a previous study conducted in Botswana [37]. According to the previous study, single and married participants had better QOL than those who were separated/widowed [18,37], which is consistent with the finding of this study. Never married people living with diabetes had better life satisfaction, which is inconsistent with a study conducted in Canada [24]. The possible reason might be that single people living with diabetes tend to perform their self-care activities alone. This finding demonstrated a significant worry due to diabetes. This finding was consistent with a study conducted in Spain [39].

The strengths of this study include the involvement of a large sample size to test the psychometric properties of the DQOL and the fact that factor-solutions were formed by EFA. The limitations of this study include the fact that the recruitment of the subjects was by convenience and thus may not be representative of all adults living with T2D who speak Afaan Oromoo in Ethiopia. Nevertheless, the hospital is one of the largest hospitals in Western Ethiopia, and many people living with diabetes attend medical check-ups there. Another limitation of this study was that test-retest reliability was not examined due to the COVID-19 pandemic, and the medical follow-up visits for diabetes in the center were delayed beyond the subject recruitment period.

\section{Conclusion}

The 34-item DQOL-AO provided preliminary evidence as a reliable and valid tool to measure QOL among adults living with T2D who speak Afaan Oromoo. Future research should assess the psychometric properties, like test-retest reliability, and the predictive validity of the 34-item DQOL-AO among people living with Type 2 diabetes.

\section{Abbreviations}

ANOVA Analysis of Variance

CVI Content validity index

DQOL Diabetes Quality of Life 
DQOL-AO Diabetes Quality of Life-Afaan Oromoo

EFA Exploratory factor analysis

IDF International Diabetes Federation

KMO Kaiser-Meyer-Olkin

QOL Quality of life

T2D Type 2 diabetes

\section{Declarations}

\section{Acknowledgments}

We would like to thank those who participated in the translation and the expert committee for their feedback. We also thank Nekemte Specialized Hospital for permission to conduct the study. We also extend our thanks to Tung Wah College for supporting the article processing charge of the publication.

\section{Funding}

The fund for translation and data collection was obtained from The Hong Kong Polytechnic University and the article processing charge was covered by the Tung Wah College.

\section{Availability of data and materials}

The dataset, and the DQOL-AO scale are not available publicly but are available from Dereje Chala Diriba on the request.

\section{Authors' contributions}

Dereje Chala Diriba, Doris Y.P. Leung, and Lorna K.Y. Suen conceived and designed the study as well as supervised the scale translation process. Dereje Chala Diriba supervised the data collection, Dereje Chala Diriba, and Doris Y.P. Leung performed the statistical analysis. All authors have developed and critically reviewed the manuscript.

\section{Ethics approval and consent to participate}

The study was approved by the human subject's ethics committee of The Hong Kong Polytechnic University. The written informed consent was received from each participant.

\section{Consent for publication}

All authors agree to publish. 


\section{Competing interest}

None of the authors declare a conflict of interest.

\section{References}

1. World Health Organization. 2008-2013 action plan for the global strategy for the prevention and control of noncommunicable diseases: prevent and control cardiovascular diseases, cancers, chronic respiratory diseases and diabetes. World Health Organization, Geneva, Switzerland, 2009.

2. International Diabetes Federation. IDF diabetes atlas, ninth edition 2019. International Diabetes Federation, Brussels, Belgium, 2019.

3. Walker J, Bradley C. Assessing the quality of life of adolescents with diabetes: using the SEIQoL, DQoL, patient and diabetes specialist nurse ratings. Practical Diabetes International. 2002;19(5):1414. https://doi.org/10.1002/pdi.348.

4. Rubin RR. Diabetes and quality of life. Diabetes spectrum. 2000;13(1):21. https://doi.org/1002/(sici)1520-7560(199905/06)15:3<205::aid-dmrr29>3.0.co;2-o.

5. Trikkalinou A, Papazafiropoulou AK, Melidonis A. Type 2 diabetes and quality of life. World Journal of Diabetes. 2017;8(4):120. https://doi.org/4239/wjd.v8.i4.120.

6. Watkins KW, Connell CM, Fitzgerald JT, Klem L, Hickey T, Ingersoll-Dayton B. Effect of adults' selfregulation of diabetes on quality-of-life outcomes. Diabetes Care. 2000;23(10):1511-5. https://doi.org/2337/diacare.23.10.1511.

7. Singh H, Bradley C. Quality of life in diabetes. International Journal of Diabetes in Developing Countries. 2006;26(1):7-10. https://doi.org/1002/(sici)1520-7560(199905/06)15:3<205::aiddmrr29>3.0.co;2-o.

8. Jones $A$, Vallis $M$, Pouwer $F$. If it does not significantly change HbA1c levels, why should we waste time on it? A plea for the prioritization of psychological well-being in people with diabetes. Diabetic Medicine. 2015;32(2):155-63. https://doi.org/1111/dme.12620.

9. Speight J, Holmes-Truscott E, Hendrieckx C, Skovlund S, Cooke D. Assessing the impact of diabetes on quality of life: what have the past 25 years taught us? Diabetic Medicine. 2020;37(3):483-92. https://doi.org/10.1111/dme.14196.

10. Nair R, Kachan P. Outcome tools for diabetes-specific quality of life: Study performed in a private family practice clinic. Canadian Family Physician. 2017;63(6):e310-e5.

11. Deshpande PR, Rajan S, Sudeepthi BL, Nazir CA. Patient-reported outcomes: a new era in clinical research. Perspectives in Clinical Research. 2011;2(4):137. https://doi.org/4103/2229-3485.86879.

12. Food Drug Administration. Guidance for industry: patient-reported outcome measures: use in medical product development to support labeling claims. Federal Register. 2009;74(235):65132-3.

13. Velentgas P, Dreyer NA, Nourjah P, Smith SR, Torchia MM. Developing a protocol for observational comparative effectiveness research: a user's guide: Government Printing Office, 2013. 
14. Bujang MA, Adnan TH, Mohd Hatta NKB, Ismail M, Lim CJ. A Revised Version of Diabetes Quality of Life Instrument Maintaining Domains for Satisfaction, Impact, and Worry. Journal of Diabetes Research. 2018;2018:5804687. https://doi.org/10.1155/2018/5804687.

15. Bujang MA, Ismail M, Hatta N, Othman SH, Baharum N, Lazim SSM. Validation of the Malay version of Diabetes Quality of Life (DQOL) Questionnaire for Adult Population with Type 2 Diabetes Mellitus. The Malaysian Journal of Medical Sciences: MJMS. 2017;24(4):86-96. https:// doi.org/10.21315/mjms2017.24.4.10.

16. Huang IC, Liu JH, Wu AW, Wu MY, Leite W, Hwang CC. Evaluating the reliability, validity and minimally important difference of the Taiwanese version of the diabetes quality of life (DQOL) measurement. Health Qual Life Outcomes. 2008;6:87. https://doi.org/1186/1477-7525-6-87.

17. Jin X, Liu GG, Gerstein HC, Levine MAH, Steeves K, Guan H, et al. Item reduction and validation of the Chinese version of the diabetes quality-of-life measure (DQOL). Health Qual Life Outcomes. 2018;16(1):78. https://doi.org/1186/s12955-018-0905-z.

18. Jacobson AM, de Groot M, Samson JA. The evaluation of two measures of quality of life in patients with type I and type II diabetes. Diabetes Care. 1994;17(4):267-74. https://doi.org/2337/diacare.17.4.267.

19. The DCCT Research Group. Reliability and validity of a diabetes quality-of-life measure for the diabetes control and complications trial (DCCT). Diabetes Care. 1988;11(9):725-32. https://doi.org/2337/diacare.11.9.725

20. Brasil F, Brasil AMB, Pontarolo R, Correr CJ. Development of the Brazilian brief version of the Diabetes Quality of Life Measure (DQOL-Brazil-8). Revista Brasileira de Epidemiologia. 2015;18:94352. https://doi.org/1590/1980-5497201500040021

21. Brasil F, Pontarolo R, Correr CJ. Qualidade de vida em adultos com diabetes tipo 1 e validade do DQOL-Brasil. Journal of Basic Applied Pharmaceutical Sciences. 2014;35(1).

22. Yildirim A, Akinci F, Gozu H, Sargin H, Orbay E, Sargin M. Translation, cultural adaptation, crossvalidation of the Turkish diabetes quality-of-life (DQOL) measure. Quality of Life Research. 2007;16(5):873-9.https://doi.org/1007/s11136-007-9172-x.

23. Pakpour $A H$, Saffari $M$, Burri A. Translation and validation of an Iranian version of the Diabetes Quality of Life measure. Journal of Diabetes Investigation. 2012;3(5):471-8. https://doi.org/1111/j.2040-1124.2012.00217.x.

24. Imayama I, Plotnikoff RC, Courneya KS, Johnson JA. Determinants of quality of life in adults with type 1 and Type 2 Health and Quality of Life Outcomes. 2011;9. https://doi.org/10.1186/1477-75259-115

25. Feyisa BR, Yilma MT, Tolessa BE. Predictors of health-related quality of life among patients with diabetes on follow-up at Nekemte Specialised Hospital, Western Ethiopia: A cross-sectional study. BMJ Open. 2020;10(7). https://doi.org/1136/bmjopen-2019-036106.

26. Aschalew AY, Yitayal M, Minyihun A. Health-related quality of life and associated factors among patients with diabetes mellitus at the University of Gondar referral hospital. Health Qual Life 
Outcomes. 2020;18(1):62. https://doi.org/1186/s12955-020-01311-5.

27. Wikipedia tfe. Oromo Language: Wikipedia, the free encyclopedia; 2021 [updated February 1, 2021. Available from: https://en.wikipedia.org/wiki/Oromo_language.

28. Beaton D, Bombardier C, Guillemin F, Ferraz MB. Recommendations for the cross-cultural adaptation of the DASH \& QuickDASH outcome measures. Institute for Work \& Health. 2007;1(1):1-45.

29. Beaton DE, Bombardier C, Guillemin F, Ferraz MB. Guidelines for the process of cross-cultural adaptation of self-report measures. 2000;25(24):3186-91. https://doi.org/10.1097/00007632200012150-00014.

30. Cristobal E, Flavian C, Guinaliu M. Perceived e-service quality (PeSQ). 2007. https://doi.org/10.1108/09604520710744326.

31. Nunnally JC. Psychometric theory 3E: Tata McGraw-Hill education; 1994.

32. Garin O. Ceiling Effect. In: Michalos AC, editor. Encyclopedia of Quality of Life and Well-Being Research. Dordrecht: Springer Netherlands; 2014. p. 631-3. https://doi.org/1007/978-94-007-0753-5.

33. Terwee CB, Bot SDM, de Boer MR, van der Windt DAWM, Knol DL, Dekker J, et al. Quality criteria were proposed for measurement properties of health status questionnaires. Journal of Clinical Epidemiology. 2007;60(1):34-42. https://doi.org/1016/j.jclinepi.2006.03.012.

34. Yusoff MSB. ABC of content validation and content validity index calculation. Educational Resource. 2019;11(2). https://doi.org/21315/eimj2019.11.2.6.

35. American Diabetes Association. Diabetes Advocacy: Standards of Medical Care in Diabetes-2021. Diabetes Care. 2021;44:S221-S2. https://doi.org/10.2337/dc21-Sint.

36. Schrepp M. On the Usage of Cronbach's Alpha to Measure Reliability of UX Scales. Journal of Usability Studies. 2020;15(4):247-58. http://uxpajournal.org.

37. Rwegerera GM, Moshomo T, Gaenamong M, Oyewo TA, Gollakota S, Rivera YP, et al. Health-related quality of life and associated factors among patients with diabetes mellitus in Botswana. Alexandria Journal of Medicine. 2018;54(2):111-8. https://doi.org/10.1016/j.ajme.2017.05.010.

38. Cheng AY, Tsui EY, Hanley AJ, Zinman B. Developing a quality of life measure for Chinese patients with diabetes. Diabetes Research and Clinical Practice. 1999;46(3):259-67. https://doi.org/1016/s0168-8227(99)00091-1.

39. Rodríguez-Almagro J, García-Manzanares Á, Lucendo AJ, Hernández-Martínez A. Health-related quality of life in diabetes mellitus and its social, demographic and clinical determinants: A nationwide cross-sectional survey. Journal of Clinical Nursing. 2018;27(21-22):4212-23. https://doi.org/10.1111/jocn.14624. 